\author{
이탈리안 라이그라스 재배지에서 제초제 사용에 의한 \\ 광대나물 방제
}

김기용*·최기준 - 이상훈 · 이기원 · 김원호 - 정민웅 · 서 성·김맹중 · 지희정

\title{
Weed Control of Henbit Deadnettle Using Herbicide on Cultivating Field of Italian Ryegrass
}

\author{
Ki-Yong Kim*, Gi Jun Choi, Sang-Hoon Lee, Ki-Won Lee, Won Ho Kim, Min Woong Jung, \\ Sung Seo, Meing Jooung Kim and Hee Chung Ji
}

\begin{abstract}
This experiment was carried out to find effective weed control method of henbit deadnettle (Lamium amplexicaule L.) on cultivating field of Italian ryegrass (Lolium multiflorum Lam) using herbicide in Grassland and Forages Division, National Institute of Animal Science, RDA, Cheonan from 2008 to 2009. When Onehof was treated two times of spray, weed control ratio was most high as $90 \%$, but this method can not be used because of much damage to Italian ryegrass. When MCPP was treated two times of spray, weed control ratio was high as $82 \%$, and damage to Italian ryegrass was very insignificant. Especially, when the spray of MCPP was treated two times, dry matter yield of Italian ryegrass was $11,427 \mathrm{~kg} / \mathrm{ha}$, but that of non treatment was $1,658 \mathrm{~kg} / \mathrm{ha}$. That is to say, forage harvest was impossible in non treatment field. According to these results, to control henbit deadnettle on cultivating field of Italian ryegrass using herbicide, you need to treat with two times of spray of MCPP in mid-March. If you do, you can get regular harvest as much as $11,427 \mathrm{~kg} / \mathrm{ha}$.
\end{abstract}

(Key words : Italian ryegrass, Henbit deadnettle, Weed control, Herbicide, MCPP)

\section{I. 서 론}

이탈리안 라이그라스(Lolium multiflorum Lam) 는 초기생육이 왕성하며, 수량성과 사료가치가 높고, 가축의 기호성이 우수할 뿐만 아니라 내 습성이 우수하여, 답리작으로 양질조사료를 생 산하기에 적합한 사료작물이다. 더욱이 근래에 심화되고 있는 지구온난화 영향은, 따뜻한 기 후에서 생산성이 높아지는 이탈리안 라이그라 스의 재배적 특성을 고려할 때 (이 등, 1992),
양질의 자급조사료 확대생산에 무엇보다 중요 한 작물이라 할 수 있다.

농촌진흥청 국립축산과학원에서는 추위에 강 하면서도 숙기가 빠른 품종을 육성해 왔다. 지 금까지 육성한 이탈리안 라이그라스 품종은 10 품종으로서 조생종 3품종 (코윈어리, 코스피드, 코그린), 중생종 1 품종 (코윈마스터), 만생종 6 품종(화산 101호, 화산 102호, 화산 103호, 화 산 104호, 코위너, 화산 106호)이 있으며 (최 등, 2000; 최 등, 2001a; 최 등, 2001b; 최 등,

농촌진흥청 국립축산과학원 (National Institute of Animal Science, Cheonan 330-801, Korea)

Corresponding author: Ph. D. Hee Chung Ji, National Institute of Animal Science, Cheonan 330-801, Korea. Tel: +82-41-580-6749, E-mail: cornhe@korea.kr 
2005; 최 등, 2006a; 최 등, 2006b; 최 등 2008), 최근 극조생종 그린팜을 육성하여 품종출원 중 에 있다.

국내에서 이탈리안 라이그라스 재배면적은 2007년 21.7천 ha, 2008년 35천 ha, 2009년 52.2 천 ha로서 재배면적이 급속히 늘어나고 있으며, 월동 사료작물 중 재배면적이 가장 많다. 이탈 리안 라이그라스는 대부분 제초작업 없이 재배 하고 있지만, 일부 경작지에서는 잡초가 많아 제초를 하지 않으면 생산량이 크게 떨어지는 경우도 있다. 논에서는 대개 뚝새풀 (Alopecurus aequalis Sobol)이 문제가 되며, 밭에서는 광대 나물 (Lamium amplexicaule L.), 쇠별꽃 (Stellaria aquatica L.) 등 월년생 잡초가 문제가 된다. 특 히 광대나물은 이탈리안 라이그라스와 자라는 시기가 비슷하고 이른 봄에 왕성하게 자라는 특성이 있어서 이탈리안 라이그라스 재배지에 우점될 경우 정상적인 조사료 생산이 불가능하 게 된다.

본 연구에서는 이탈리안 라이그라스 재배 포 장에서 파종 후 겨울을 넘기는 동안 광대나물 이 발생하여, 월동 후 우점으로 이탈리안 라이 그라스의 생육이 위축되므로, 이탈리안 라이그 라스 생육 재생기에 광엽잡초 방제용 제초제를 살포했을 때의 잡초방제효과를 구명코자 했다.

\section{ㅍ. 재료 및 방법}

\section{1. 시험재료 및 장소}

시험재료는 이탈리안 라이그라스(Lolium multi- florum Lam) 조생종 코윈어리와 월년생 광엽잡 초인 광대나물 (Lamium amplexicaule L.)을 사용 하였으며, 시험장소는 국립축산과학원 초지사 료과(천안)의 이탈리안 라이그라스 재배포장 중 광대나물이 우점된 곳을 선정하였다. 이탈 리안 라이그라스 재배지에서 광대나물의 방제 법을 구명하기 위해 2008년부터 2009년까지 2 년간 연구를 수행하였다.

\section{2. 사용 제초제 및 약량}

이탈리안 라이그라스 재배포장에서 광대나물 을 방제하기 위한 제초제는 광엽잡초를 없애는 선택성 제초제 4종을 사용하였으며, 제초제명, 약량 및 살포량은 Table 1과 같다. 실험에 사용 한 모든 제초제는 시중 농약사에서 구입하여 사용하였다.

$\mathrm{MCPP}$ 는 (주)영일케미컬에서 제조한 제초제 로서, 페녹시계로 분류되고 주성분은 mecoprop 로서 적용잡초는 클로버류, 광엽잡초 등이며 사용시기는 생육초기이다. 원호프는 (주)한국삼 공에서 제조한 제초제로서, 설포닐 우레아계로 분류되고 주성분은 nicosulfuron로서 적용잡초 는 일년생잡초, 화본과잡초 4 엽기 등이며 사용 시기는 옥수수 3 5엽기이다. 반벨은 (주)성보화 학에서 제조한 제초제로서, 주성분은 dicamba 이고 적용잡초는 클로버류, 광엽잡초, 잡관목 등이며 사용시기는 생육초기이다. 밧사그란은 (주)성보화학에서 제조한 제초제로서, 주성분이 bentazone으로서 적용잡초는 일년생잡초, 광엽 잡초 등이며 사용시기는 3 5엽기이다.

Table 1. Name of herbicide and dosage used in Italian ryegrass field predominated with henbit deadnettle (Lamium amplexicaule L.)

\begin{tabular}{cclcc}
\hline Herbicide & Component & \multicolumn{1}{c}{ Applied weeds } & $\begin{array}{c}\text { Dosage } \\
\left(\mathrm{ml} / 20 \ell \mathrm{H}_{2} \mathrm{O}\right)\end{array}$ & $\begin{array}{c}\text { Spray } \\
(\ell / 10 \mathrm{a})\end{array}$ \\
\hline \hline MCPP & mecoprop & Clover, Broadleaf weed & $67 \mathrm{ml}$ & $150 \ell$ \\
Wonhof & nicosulfuron & Annual weed & $20 \mathrm{ml}$ & $100 \ell$ \\
Banbel & dicamba & Clover, Broadleaf weed & $17 \mathrm{ml}$ & $120 \ell$ \\
Batsagran & bentazone & Annual weed, Broadleaf weed & $60 \mathrm{ml}$ & $100 \ell$ \\
\hline
\end{tabular}


3. 이탈리안 라이그라스 파종 및 시비

이탈리안 라이그라스 ‘코윈어리’의 파종량은 ha당 $30 \mathrm{~kg}$ 으로 하였으며, 파종시기는 9 월 20 일, 파종방법은 $15 \mathrm{~cm}$ 세조파로 하였다. 제초제 처리를 위한 시험구 배치는 난괴법 3 반복 $(2 \times$ $4=6 \mathrm{~m}^{2}$ )로 하였다. 시비량은 $1 \mathrm{ha}$ 당 $\mathrm{N}-\mathrm{P}_{2} \mathrm{O} 5$ $\mathrm{K}_{2} \mathrm{O}=140-150-150 \mathrm{~kg}$ 로 하였으며, 시비방법은 인산 $\left(\mathrm{P}_{2} \mathrm{O}_{5}\right)$ 과 칼리 $\left(\mathrm{K}_{2} \mathrm{O}\right)$ 는 $1 \mathrm{ha}$ 당 기비로 75 $\mathrm{kg}$ 을 시비하고 이른 봄 (3월 5일)에 추비로 75 $\mathrm{kg}$ 을 시비하였으며, 질소 $(\mathrm{N})$ 는 $1 \mathrm{ha}$ 당 기비로 $40 \mathrm{~kg}$ 을 시비하고 이른 봄에 추비로 $100 \mathrm{~kg}$ 을 시비하였다.

\section{4. 제초제 처리 및 조사내용}

시험에 사용한 제초제의 종류와 약량은 농촌 진흥청 국립농업과학원의 자문을 받아 법적 허 용범위 내에서 사용하였으며, 제초제 처리는 무처리, MCPP, 원호프, 반벨, 밧사그란으로 하 였으며, 약량은 정량으로 살포하였고, 1 회 살포 한 것과 10 일 간격으로 2 회 살포한 처리를 두 었다. 제초제는 시중에서 구입한 소형 분무기 를 사용하여 살포하였으며, 제초제 살포시기는 광대나물이 생육을 시작한 3월 9일에 1차 살포 하였고, 10 일 후 3월 19일에 2차 살포하였으며, 약제 2차 살포 30 일 후에 이탈리안 라이그라스 생육상태와 잡초 억제율을 달관으로 조사하였 고, 5월 14일 (개화기)에 이탈리안 라이그라스
를 수확하여 생초수량과 건물수량을 조사하 였다.

\section{III. 결과 및 고찰}

1. 제초제 처리효과

국내육성 이탈리안 라이그라스 신품종 '코윈 어리, 재배지에서 광대나물의 방제법을 구명하 기 위해 연구를 수행한 결과, 잡초 억제율과 이탈리안 라이그라스의 피해 정도는 Table 2와 같다. 잡초 억제율은 제초제 1 회 살포 시 원호 프 $65 \%, \mathrm{MCPP} 55 \%$, 밧사그란 $26 \%$, 반벨 $25 \%$ 순으로 높았으며, 제초제 1 차 살포 10 일 뒤에 한 번 더 살포한 경우(2회 살포), 원호프 $90 \%$, $\mathrm{MCPP} 82 \%$, 밧사그란 $63 \%$, 반벨 $60 \%$ 순으로 높게 나타났다. 하지만 $\mathrm{MCPP}$ 를 2회 살포한 경 우에도 광대나물은 완전히 죽지 않았으나, 잎 과 줄기가 고꾸라져 더 이상의 생육은 되지 않 았으며, 약해를 입어 개화가 되지 않았다.

김 등 (1999)이 외래잡초 애기수영(Rumex acetosella L.)에 MCPP와 반벨을 처리했을 때 처리 2 일 후 애기수영의 잎에서 황백화현상이 나타나고 $60 \%$ 이상의 잡초 억제율을 나타냈다 고 보고하였는데, 광대나물의 경우에는 확실한 황백화현상은 나타나지 않았다. 단지 무처리구 의 광대나물 잎은 진한 녹색인데 비해 $\mathrm{MCPP}$ 등 제초제를 처리한 시험구의 광대나물 잎은 연한 녹색 또는 연두색으로 변하는 약해를 나

Table 2. Effect of herbicide treatment on Italian ryegrass (IRG) damage and weed control

\begin{tabular}{ccccccc}
\hline \multirow{2}{*}{ Treatments } & \multicolumn{2}{c}{ One time of spray } & & \multicolumn{2}{c}{ Two times of spray } \\
\cline { 2 - 3 } \cline { 5 - 6 } & $\begin{array}{c}\text { IRG damage } \\
(1 \sim 9)^{*}\end{array}$ & $\begin{array}{c}\text { Weed control } \\
(\%)\end{array}$ & & $\begin{array}{c}\text { IRG damage } \\
(1 \sim 9)^{*}\end{array}$ & $\begin{array}{c}\text { Weed control } \\
(\%)\end{array}$ \\
\hline \hline Non treatment & 9 & & & 9 & 0 \\
MCPP & 9 & 55 & & 8 & 82 \\
Wonhof & 3 & 65 & & 2 & 90 \\
Banbel & 8 & 25 & & 8 & 60 \\
Batsagran & 8 & 26 & & 8 & 63 \\
\hline
\end{tabular}

$(1 \sim 9)^{*}: 1=$ High damage, $9=$ Non damage 
타냈다. 한편 김 등 (2003)은 고랭지 목초지에 서 애기수영에 MCPP를 1회 처리했을 때 77 $83 \%$ 의 잡초 억제율을 나타냈고, 2 회 처리한 경 우에는 $93 \%$ 의 잡초 억제율을 나타냈다고 보고 하였다. 이 외에도 $\mathrm{MCPP}$ 처리나 광대나물 방 제에 대한 많은 보고들이 있다 (구자옥 등, 1995 ; 김성문 등, $2000 ; \mathrm{Kwon}, 2004$; 다이엥리 와 컬크호와트, 2007).

한편 이탈리안 라이그라스의 피해 정도는 제 초제 1 회 살포 시 원호프 3 , 반벨과 밧사그란 8, MCPP 9 순으로 높았으며, 제초제 2회 살포 시 원호프 2, 반벨, 밧사그란 및 $\mathrm{MCPP} 8$ 순으 로 높게 나타났다. 잡초 억제율은 원호프 2회 처리구에서 $90 \%$ 로 가장 높았으나, 이탈리안 라 이그라스의 피해도 커서 사용할 수 없는 방법 이었으며, 그 다음으로 $\mathrm{MCPP}$ 가 1회 처리구에 서 $55 \%, 2$ 회 처리구에서 $82 \%$ 로 방제효과가 높 고 이탈리안 라이그라스의 피해도 약해서 광대 나물을 방제하는데 가장 적합한 방법으로 밝혀 졌다.

\section{2. 이탈리안 라이그라스의 수량성}

이탈리안 라이그라스 재배포장에서 광대나물 을 방제하기 위해 4종의 제초제를 살포한 다 음, 5 월 중순 이탈리안 라이그라스 개화기에 처리구별로 수확하여 생초수량과 건물수량을 조사한 결과는 Table 3 과 같다.
제초제 1 회 살포 시 ha당 건물수량은 $\mathrm{MCPP}$ $7,837 \mathrm{~kg}$, 반벨 $6,322 \mathrm{~kg}$, 밧사그란 $5,780 \mathrm{~kg}$, 원 호프 $2,170 \mathrm{~kg}$ 순으로 높았으며, 제초제 1 차 살 포 10 일 뒤에 한 번 더 살포한 경우(2회 살포) ha당 건물수량은 MCPP $11,427 \mathrm{~kg}$, 반벨 9,520 $\mathrm{kg}$, 밧사그란 $8,825 \mathrm{~kg}$, 원호프 $3,035 \mathrm{~kg}$ 순으로 높게 나타났다 $(\mathrm{p}<0.05)$. 김 등 (2008)은 이탈리 안 라이그라스 재배포장에서 $\mathrm{MCPP} 1.5$ 배액을 처리함으로써 쇠별꽃 (Stellaria aquatica L.)을 $85 \%$ 억제하여 정상적인 조사료 생산을 가능 케 했다고 보고했는데, 농약사용 규정상 1.5 배 액을 처리하는 것은 허용되지 않기 때문에 본 연구에서는 $\mathrm{MCPP}$ 정량을 2회 살포하여 처리 하였다. 한편 제초제를 살포하지 않은 무처리 구는 ha당 건물수량이 $1,658 \mathrm{~kg}$ 으로서 원호프를 2회 살포하여 약해를 심하게 받았을 때의 건물 수량 $3,035 \mathrm{~kg}$ 보다 오히려 낮았다 $(\mathrm{p}<0.05)$. 결 국 광대나물이 심하게 우점한 경우 제초제를 사용하지 않으면 정상적인 조사료 생산을 기대 하기 어려운 것으로 판단된다.

Fig. 1은 제초제 처리 30일 후 처리구별로 촬영한 사진자료로서 $\mathrm{A}$ 는 제초제 1 회 처리구 사진이고, $\mathrm{B}$ 는 제초제 2회 처리구 사진이다. 제초제를 처리하지 않은 시험구의 광대나물은 생육이 왕성하고 모두 개화해서 이탈리안 라이 그라스를 찾아볼 수 없었다. 제초제 처리구에 서는 1 회 처리에 비해 2회 처리 시 광대나물 생육이 더 많이 억제되었음을 볼 수 있으며,

Table 3. Yield of fresh weight and dry matter of Italian ryegrass after several herbicide treatment

\begin{tabular}{cccccc}
\hline \multirow{2}{*}{ Treatments } & \multicolumn{2}{c}{ One time of spray } & & \multicolumn{2}{c}{ Two times of spray } \\
\cline { 2 - 3 } \cline { 5 - 6 } & $\begin{array}{c}\text { Fresh weight } \\
(\mathrm{kg} / \mathrm{ha})\end{array}$ & $\begin{array}{c}\text { Dry matter } \\
(\mathrm{kg} / \mathrm{ha})\end{array}$ & & $\begin{array}{c}\text { Fresh weight } \\
(\mathrm{kg} / \mathrm{ha})\end{array}$ & $\begin{array}{c}\text { Dry matter } \\
(\mathrm{kg} / \mathrm{ha})\end{array}$ \\
\hline \hline Non treatment & $8,450^{\mathrm{d}}$ & $1,658 \mathrm{e}$ & & $8,450^{\mathrm{e}}$ & $1,658^{\mathrm{e}}$ \\
MCPP & $44,530^{\mathrm{a}}$ & $7,837^{\mathrm{a}}$ & & $61,148^{\mathrm{a}}$ & $11,427^{\mathrm{a}}$ \\
Wonhof & $13,110^{\mathrm{c}}$ & $2,170^{\mathrm{d}}$ & & $13,967^{\mathrm{d}}$ & $3,035^{\mathrm{d}}$ \\
Banbel & $37,235^{\mathrm{b}}$ & $6,322^{\mathrm{b}}$ & & $48,510^{\mathrm{b}}$ & $9,520^{\mathrm{b}}$ \\
Batsagran & $37,590^{\mathrm{b}}$ & $5,780^{\mathrm{c}}$ & & $45,601^{\mathrm{c}}$ & $8,825^{\mathrm{c}}$ \\
\hline
\end{tabular}

${ }^{\text {abcde }}$ Means in the same column with different letter were significantly different $(\mathrm{p}<0.05)$. 


\section{A One time of spray}

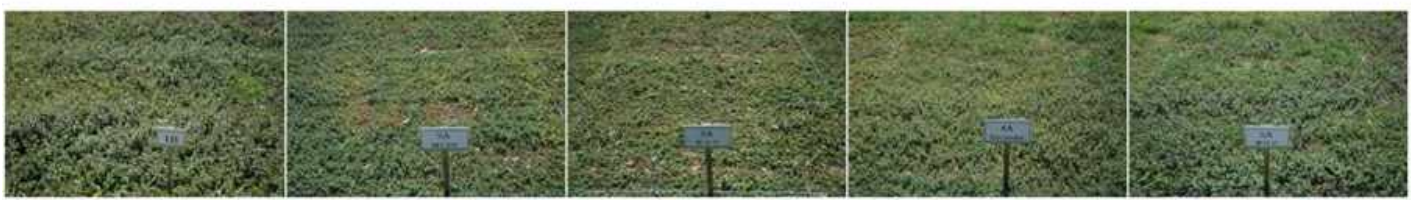
Non treat.
MCPP
Wonhof
Banbel
Batsagran

\section{B Two times of spray}

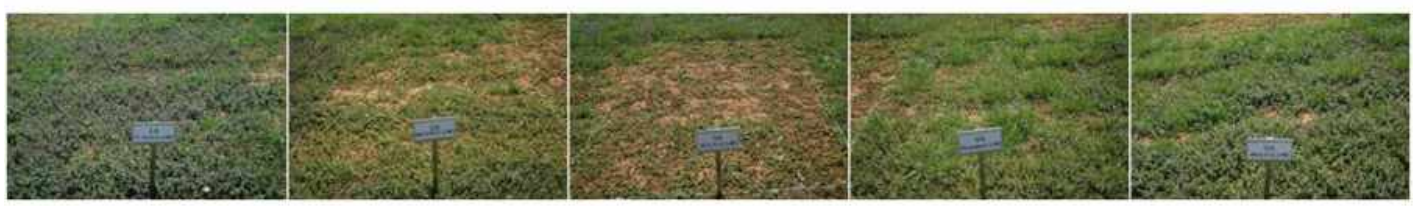

Non treat.

MCPP

Wonhof

Banbel

Batsagran

Fig. 1. Effect of herbicide treatment on Italian ryegrass damage and weed control.

제초제 2회 처리구에서 원호프는 이탈리안 라 이그라스도 약해를 입어 빈 땅이 많이 보이는 상태이고, $\mathrm{MCPP}$ 의 경우에는 광대나물만 억제 되고 이탈리안 라이그라스는 약해를 거의 입지 않았음을 볼 수 있다. 따라서 이후 이탈리안 라이그라스가 정상적인 생육을 할 수 있어서 5 월 중순 수확 시 $\mathrm{MCPP}$ 를 2회 처리한 구에서 는 ha당 건초수량이 $11,427 \mathrm{~kg}$ 으로서 정상수확 이 가능하였다.

결론적으로 이탈리안 라이그라스 재배포장에 서 월년생 잡초 광대나물을 방제하려면 3월 중 순에 $\mathrm{MCPP}$ 를 10 일 간격으로 2회 살포하면 되 며, 조사료 생산량도 정상적인 수량을 얻을 수 있을 것으로 사료된다.

IV. 요 약

본 논문은 국내육성 IRG 신품종 “코윈어리” 재배지에서 광대나물의 방제법을 구명하기 위 해 농촌진흥청 국립축산과학원 초지사료과에서 2008년부터 2009년까지 2년간 연구한 결과이 다. 잡초 억제율은 원호프 2회 처리구에서 $90 \%$
로 가장 높았으나, IRG 피해도 커서 사용할 수 없으며, 그 다음으로 $\mathrm{MCPP}$ 2회 처리구에서는 잡초 억제율이 $82 \%$ 로 방제효과가 높고 IRG 피 해도 적으며 잡초방제 효과가 우수한 것으로 나타났다. 광대나물 방제를 위해 $\mathrm{MCPP}$ 를 10 일 간격으로 2 회 살포한 경우, 건물생산량은 $\mathrm{ha}$ 당 $11,427 \mathrm{~kg}$ 으로서 무처리구의 $1,658 \mathrm{~kg}$ 에 비해 $598 \%$ 증가하였다. 다시 말해서 $\mathrm{MCPP}$ 를 처리 하지 않으면 조사료 수확이 불가능하였다. 이 상의 결과에서 이탈리안 라이그라스 재배포장 에서 월년생 잡초 광대나물을 방제하려면 3월 중순에 $\mathrm{MCPP}$ 를 10 일 간격으로 2회 살포하면 되며, 조사료 생산량도 $\mathrm{ha}$ 당 $11,427 \mathrm{~kg}$ 으로서 정상적인 수량을 얻을 수 있는 것으로 판단 된다.

\section{$\mathrm{V}$. 인 용 문 헌}

1. 구자옥, 이병렬, 천상욱, 한성욱. 1995. 안개에 기 인하는 한국들잔디 (Zoysia japonica)의 잡초경합 및 제초제반응 특이성. 한국잡초학회지. 15 (4):262-269. 
2. 김맹중, 서 성, 윤세형, 최기준, 김기용, 지희정, 이상훈, 김종근. 2008. 이탈리안 라이그라스 재배 포장에서 쇠별꽃 (Stellaria aquatica L.) 잡초방제 효과. 한국초지조사료학회 학술발표.

3. 김성문, 김용호, 황기환, 안문섭, 허장현, 한대성. 1999. 애기수영의 화학적 방제를 위한 제초제 선 발 및 선발 제초제의 살초효과. 한국농약과학회 지. 3(3):45-53.

4. 김성문, 오혜영, 김용호, 조준모, 허장현, 한대성. 2000. 감초경작지의 잡초방제를 위한 제초제 선 발. 한국농약과학회지. 4(4):81-86.

5. 김영근, 정종원, 최연식, 임영철, 한성윤, 나기준. 2003. 애기수영이 우점한 고랭지 목초지에 제초 제의 처리가 잡초방제 및 목초생육에 미치는 영 향. 한국동물자원과학회지. 45(5):865-874.

6. 다이엥리, 컬크호와트. 2007. 캔터키블루그래스 잔디에서의 제초제와 비료의 단독과 혼용처리에 의한 잡초방제. 한국잔디학회지. 21(1):69-79.

7. 이호진, 채제천, 이석순, 구자옥, 최진용. 1992. 신제 사료작물학. 향문사. pp. 218-224.

8. 최기준, 임영철, 김기용, 김맹중, 지희정, 이상훈, 박형수, 문정섭, 이은섭, 서 성. 2008. 내한 중생 이탈리안 라이그라스 신품종 “코윈마스터”. 한초 지. 28(3):177-184.

9. 최기준, 임영철, 김기용, 성병렬, 임용우, 김맹중, 임근발, 서 성. $2006 \mathrm{~b}$. 내한 다수성 이탈리안 라
이그라스 신품종 ‘코위너' 한초지. 26(3):171-176.

10. 최기준, 임영철, 임용우, 성병렬, 김맹중, 김기용, 서성. 2006a. 내한 조숙성 이탈리안 라이그라스 신품종 ‘코그린'. 한초지. 26(1):9-14.

11. 최기준, 임용우, 김기용, 최순호, 성병렬, 김원호, 신동은, 임영철. 2000. 내한 다수성 이탈리안 라 이그라스 신품종 “화산 101호”. 한초지. 20(1): $1-6$.

12. 최기준, 임용우, 성병렬, 임영철, 김맹중, 김기용, 박근제, 박남건, 홍윤기, 김상록. 2005. 이탈리안 라이그라스 신품종 '화산 104호'의 생육특성과 수량성. 한초지. 25(4):275-280.

13. 최기준, 임용우, 임영철, 김기용, 성병렬, 김맹중, 박근제, 김상록. $2001 \mathrm{a}$. 이탈리안 라이그라스 “화 산 102호”의 생육특성과 수량성. 한초지. 21(3): 152-158.

14. 최기준, 임용우, 임영철, 김기용, 성병렬, 최순호, 박근제. 2001b. 이탈리안 라이그라스 “화산 103 호”의 생육특성과 수량성. 한초지. 21(3):159-165.

15. Kwon, B.-S. 2004. Effects of mecoprop wettable powder concentrations on growth and yield of flax. Plant Resources. 7(1):15-21.

(접수일: 2011년 8월 18일, 수정일 1차: 2011년 9월 10일, 수정일 2차: 2011년 10월 3일, 게재확정일: 2011년 10월 31일) 